\title{
3D printed hydrogels with oxidized cellulose nanofibers and silk fibroin for the proliferation of lung epithelial stem cells
}

\author{
Li Huang · Wei Yuan · Yue Hong • Suna Fan · Xiang Yao • Tao Ren • \\ Lujie Song $\cdot$ Gesheng Yang $\cdot$ Yaopeng Zhang $\mathbb{D}$
}

Received: 2 May 2020/Accepted: 10 October 2020/Published online: 26 October 2020

(C) Springer Nature B.V. 2020

\begin{abstract}
A novel biomaterial ink consisting of regenerated silk fibroin (SF) and 2,2,6,6-tetramethylpiperidine-1-oxyl (TEMPO)-oxidized bacterial cellulose (OBC) nanofibrils was developed for 3D printing lung tissue scaffold. Silk fibroin backbones were cross-linked using horseradish peroxide $/ \mathrm{H}_{2} \mathrm{O}_{2}$ to form printed hydrogel scaffolds. OBC with a concentration of $7 \mathrm{wt} \%$ increased the viscosity of inks during the printing process and further improved the shape fidelity of the scaffolds. Rheological measurements and image analyses were performed to evaluate inks
\end{abstract}

Electronic supplementary material The online version of this article (https://doi.org/10.1007/s10570-020-03526-7) contains supplementary material, which is available to authorized users.

L. Huang $\cdot$ S. Fan $\cdot$ X. Yao $\cdot$ G. Yang $(\bowtie)$.

Y. Zhang $(\bowtie)$

State Key Laboratory for Modification of Chemical Fibers and Polymer Materials, Shanghai Belt and Road Joint Laboratory of Advanced Fiber and Low-Dimension Materials, College of Materials Science and Engineering, Donghua University, Shanghai 201620, People's Republic of China

e-mail: gsyang@dhu.edu.cn

\section{Y. Zhang}

e-mail: zyp@dhu.edu.cn

\section{W. Yuan}

Department of Urology, Weifang People's Hospital,

Weifang Medical University, Weifang 261000,

Shandong, People's Republic of China printability and print shape fidelity. Three-dimensional construct with ten layers could be printed with ink of $1 \mathrm{SF}-2 \mathrm{OBC}(\mathrm{SF} / \mathrm{OBC}=1 / 2, \mathrm{w} / \mathrm{w})$. The composite hydrogel of $1 \mathrm{SF}-1 \mathrm{OBC}(\mathrm{SF} / \mathrm{OBC}=1 / 1, \mathrm{w} / \mathrm{w})$ printed at $25{ }^{\circ} \mathrm{C}$ exhibited a significantly improved compressive strength of $267 \pm 13 \mathrm{kPa}$ and a compressive stiffness of $325 \pm 14 \mathrm{kPa}$ at $30 \%$ strain, respectively. The optimized printing parameters for $1 \mathrm{SF}-1 \mathrm{OBC}$ were 0.3 bar of printing pressure, $45 \mathrm{~mm} / \mathrm{s}$ of printing speed and $410 \mu \mathrm{m}$ of nozzle diameter. Furthermore, OBC nanofibrils could be induced to align along the print lines over 60\% degree of orientation, which were analyzed by SEM and X-ray diffraction. The orientation of OBC nanofibrils along print lines provided physical cues for guiding the

\footnotetext{
Y. Hong · T. Ren

Department of Respiratory Medicine, Shanghai Jiao Tong University Affiliated Sixth People's Hospital,

Shanghai 200233, People's Republic of China

L. Song

Department of Urology, Shanghai Jiao Tong University Affiliated Sixth People's Hospital, Shanghai 200233,

People's Republic of China

L. Song

Shanghai Oriental Institute for Urologic Reconstruction, Shanghai 200233, People's Republic of China
} 
orientation of lung epithelial stem cells, which maintained the ability to proliferate and kept epithelial phenotype after 7 days' culture. The 3D printed SFOBC scaffolds are promising for applications in lung tissue engineering.

Keywords Silk fibroin - Bacterial cellulose nanofibrils $\cdot 3 \mathrm{D}$ printing $\cdot$ Hydrogel $\cdot$ Stem cells

\section{Introduction}

Pulmonary disease, especially COVID-19, is a worldwide public health problem recently. Transplantation of lung suffers the shortage of donors as well as inevitable immunosuppressive drugs for patients. Lung tissue engineering shows an alternative to relieve the problems of shortage of lung transplantation (Tebyanian et al. 2019) and is beneficial to the recovery of patients' lung. Biological scaffolds made by threedimensional printing technology combining regenerative cell population is an attracting candidate strategy for lung tissue engineering. Natural polymers or synthetic polymers have been introduced to the scaffold's studies of lung tissue. For example, decellularized scaffolds from human or animals, collagen type I-GAG, gelatin, polyglycolic acid (PGA), polyDL-lactic acid (PDLLA), poly lactic-co-glycolic acid (PLGA), polylactic acid (PLLA), Pluronic F-127 etc. (Tebyanian et al. 2019; Wagner et al. 2014) However, synthetic polymers sometimes fail to drive the differentiation of cultured cells (Lin et al. 2006; Mondrinos et al. 2006). In contrast, natural biomaterials are promising for constructing biomimetic extracellular matrix (ECM) for ex-vivo research of lung tissue engineering. Recently, 3D printing technology using biomaterials as inks offers a fascinating method for tissue engineering application. Various natural polymers-based biomaterials such as ECM components, alginate, chitosan, cellulose, starch, and silk fibroin, etc., have been used for bioink preparation (Aljohani et al. 2018). Proteins and polysaccharides are the commonly used natural polymers-based biomaterial inks due to their biocompatibility, biodegradability and low immunogenicity properties (McCarthy et al. 2019; Moohan et al. 2020).

Silk fibroin (SF) derived from silkworm cocoons (Bombyx mori) has been developed as an ink because of its excellent biocompatibility, low toxicity and immune reactivity in addition to its low bacterial adherence (Wlodarczyk-Biegun and Campo 2017). SF is a fascinating material for the preparation of physically crosslinked ink. It is possible to induce a sol-to-gel transition in SF conformation from random coil to $\beta$-sheet using shear force (Ghosh et al. 2008), sonication (Das et al. 2015), polyols (Jose et al. 2015), high temperature (Hu et al. 2011), low pH (Terry et al. 2004), etc. Physical cross-linking caused by dynamic and reversible bonding due to noncovalent interactions was mild and the corresponding SF hydrogel exhibited good cytocompatibility in cell-laden printing (Jungst et al. 2016). However, although the $\beta$-sheet domains of the SF hydrogel provided stiffness and tensile strength they exhibited poor elasticity (Yan 2016). Enzymes have also been adopted to produce chemically-crosslinked SF hydrogel (Chawla et al. 2018; Das et al. 2015). Approximately 5\% tyrosine residues provide the phenol functional groups in the SF sequence (Murphy and Kaplan 2009) which can form dityrosine through an enzyme-mediated reaction in horseradish peroxide (HRP) $/ \mathrm{H}_{2} \mathrm{O}_{2}$ (Kurisawa et al. 2010). The SF inks exhibited the required thinning behavior at low concentrations $(<20 \%)$ for printing prior to gelation (Chawla et al. 2018). However, it is difficult to form a self-standing construct from pristine SF solution with high shape fidelity during printing. Therefore, bulk filling agents, e.g. gelatin (Das et al. 2015), hydroxyapatite (Sun et al. 2012) or polyethylene glycol (Zheng et al. 2018) have been commonly used for SF-based inks. Even so, it has been a huge challenge for applications of SF-based inks due to their suboptimal printability and poor ECM mimicry in contemporary research.

Cellulose nanofibers have good mechanical properties and biocompatibility and are of great interest in biomedical applications (Fernandes et al. 2013; Markstedt et al. 2015; Wang et al. 2018, 2020). Furthermore, cellulose nanofibers are promising printer-friendly materials whose properties include shear thinning behavior, high zero shear viscosity, high shape fidelity, and structural stability when 3D printed (Cheng et al. 2019; Liu et al. 2019; Nimeskern et al. 2013; Schwarz et al. 2015). Various cellulosic nanomaterials including cellulose nanofibrils (CNF), cellulose nanocrystals (CNC), bacterial cellulose (BC) have been used as hydrogels or reinforced materials for $3 \mathrm{D}$ printing (Chinga-Carrasco 2018; Xu et al. 2018). BC displays 
the unique physiochemical characteristics of highly pure and crystalline in comparison with plant cellulose (Moniri et al. 2017). Recently, Dorishetty et al. reported for the first time the detailed effects of various kinds of nanocellulose, namely, $\mathrm{BC}, \mathrm{CNF}$, and CNC on the morphology, structure-property relationship, and 3D printability of the photochemically cross-linked SF/nanocellulose composite hydrogels. Results indicated that $\mathrm{SF} / \mathrm{BC}$ composite hydrogel possessed the superior mechanical performance among the hydrogels (Dorishetty et al. 2020). However, it has been found that clogging is experienced when pastes of cellulose nanofibers are used at high concentration $(>0.8 \%)$ in 3D printing, due to the large bunches of fibers. For example, only very small quantities $(0.7$ $\mathrm{wt} \%$ ) of $\mathrm{BC}$ fibers were used for the printing of complicate SF/Gelatin mixture (Huang et al. 2019b). Dorishetty et al. developed the SF/BC inks which could achieve a maximum cellulose content of about $5 \mathrm{wt} \%$ and could only print two layers structure. Higher resolution with 3D stereoscopic construct was difficult to achieve due to limited cellulose in inks (Dorishetty et al. 2020). Because TEMPO-mediated oxidation helps reduce the adhesion and provide electrostatic repulsions between microfibrils by introducing certain amount of carboxylate groups, which facilitates the dispersion of cellulose nanofibers, especially BC. Therefore, this issue could be addressed by using TEMPO-mediated oxidation and co-solvents (Dai et al. 2019). In addition, the incorporation of cellulose nanofibrils into inks provides structural similarity of 3D printed scaffolds to ECMs which possess filamentous architecture, benefitting cell growth and phenotype maintenance in addition to providing tissue with specific properties (Huang et al. 2019a; Prince and Kumacheva 2019; Theocharis et al. 2016). Therefore, artificial ECM-mimetic fibrillar hydrogels are important materials for use in tissue engineering applications.

At present, stem cell technologies have been the focus of considerable attention in organ transplantation and regenerative medicine due to their unique ability to proliferate and differentiate. However, stem cells are sensitive to their microenvironment and can be influenced by physical and chemical factors. On one hand, the poor viability, limited proliferation and undesirable differentiation of stem cells may be attributed to unsuitable matrices. On the other hand, the fate of stem cells can also be regulated by the specific design of the stem cell niche to satisfy the requirements of stem cells and thus direct their differentiation (Huang et al. 2019c; Prince and Kumacheva 2019). For example, in mature lungs, cell polarity and orientation are important in the self-renewal/differentiation of epithelial cells and can impact normal physiological processes such as epithelial tissue branching and differentiation (El-Hashash and Warburton 2011; Plosa et al. 2012). Therefore, it is of great benefit to provide essential structure and biophysical cues for lung tissue regeneration. In addition, lung tissue engineering is different from other forms of tissues engineering, for example skin or cartilage, in that it requires complex $3 \mathrm{D}$ structures comprising soft biological materials (Comber et al. 2019). However, traditional molding techniques do not easily lend themselves to the fabrication of intricate geometries or precise features. 3D bioprinting is an approach with the potential to produce scaffolds with sufficient complexity of high resolution using soft materials (Kang et al. 2016; Malda et al. 2013).

It is very challenging to print lung tissue engineering scaffolds with natural polymers-based biomaterial inks. In this study, a simple binary ink containing concentrated TEMPO oxidized bacterial cellulose (OBC) nanofibrils and SF was developed for 3D printing. SF backbones were cross-linked by horseradish peroxide (HRP)/ $\mathrm{H}_{2} \mathrm{O}_{2}$ to form printed hydrogel scaffolds, while OBC promoted the viscosity of the inks and further improved the mechanical properties and shape fidelity of the scaffolds. Additionally, the influence of fiber alignment on lung epithelial stem cells (LESCs) behaviors were investigated. The composite hydrogel scaffolds demonstrated promising potential in $3 \mathrm{D}$ implant bioprinting applications.

\section{Materials and methods}

\section{Materials}

BC bulks were obtained from Hai Nan Yeguo Foods Co., Ltd. (Haikou, China). Silkworm cocoons from $B$. mori were purchased from Tongxiang City, Zhejiang Province, China. Horseradish peroxide was purchased from Sigma Aldrich (St. Louis, MO, USA). Dulbecco's modified Eagle's medium (DMEM) and fetal bovine serum (FBS) were purchased from Gibco (USA). Calcein acetoxymethylester/ Propidium iodide 
(Calcein AM/PI) were purchased from Yeasen Biotech Co., Ltd. (Shanghai, China). Rhodamine phalloidin, 2-(4-Amidinophenyl)-6-indolecarbamidine dihydrochloride (DAPI) and 3-(4, 5-dimethylthiazol-2yl)-2, 5-diphenyl tetrazolium bromide (MTT) were purchased from Sigma-Aldrich (USA). Rabbit antiKi67, rabbit anti-p63 and fluorescein isothiocyanate (FITC) were purchased from Abcam (UK). All other chemicals were acquired from Sinopharm Chemical Reagent Co., Ltd. (Shanghai, China), were analytical grade and used as received.

\section{Preparation of OBC}

OBC was oxidized using the TEMPO/ $\mathrm{NaBr} / \mathrm{NaClO}$ system. Briefly, BC bulks were homogenized by a homogenizer (T18DS25, IKA, Germany) at $20,000 \mathrm{rpm}$ for $30 \mathrm{~min}$. Then the BC suspension was concentrated to slurry by centrifuging at $3500 \mathrm{rpm}$ for $10 \mathrm{~min}$. The solid content of $\mathrm{BC}$ was obtained by weighing method. BC suspension $(0.7 \mathrm{wt} \%)$ with $300 \mathrm{~mL}$ was used. TEMPO (1.6 wt \% BC) and $\mathrm{NaBr}$ (10 wt $\%$ BC) were added to the suspension. After 1 min later, $\mathrm{NaClO}(7.8 \mathrm{~mL})$ was immediately added to the suspension. Oxidation time was $1 \mathrm{~h}$ and $\mathrm{pH}$ was 10.5 at room temperature (Yao et al. 2017). The OBC was dialyzed in distilled water for 1 week and concentrated to $7 \mathrm{wt} \%$ by centrifuging at $12,000 \mathrm{rpm}$ for $10 \mathrm{~min}$. OBC concentration was ascertained by measuring the dry weight of OBC pastes. The process of $\mathrm{OBC}$ preparation is displayed in Fig. 1.

\section{Preparation of SF}

SF solution was prepared as reported previously (Huang et al. 2019b). Briefly, silkworm cocoons were cut into pieces and degummed twice in $0.5 \mathrm{wt} \%$ boiled sodium carbonate solution for $30 \mathrm{~min}$. The degummed silk fibers were dissolved in $9.0 \mathrm{M}$ lithium bromide solution at $40{ }^{\circ} \mathrm{C}$ for $2 \mathrm{~h}$. The SF solution was dialyzed in deionized water for $72 \mathrm{~h}$ to remove salt and then further concentrated to $20 \mathrm{wt} \%$ by air flow prior to storage at $4{ }^{\circ} \mathrm{C}$ until required. The preparation process is shown in Fig. 1.

Transmission electron microscopy (TEM)

The OBC suspension was diluted to $0.01 \mathrm{wt} \%$ and $0.001 \mathrm{wt} \%$, respectively and placed on copper grids.
TEM images were acquired using a JEM-2100 (JEOL, Japan) transmission electron microscope at $200 \mathrm{kV}$.

Ink preparation

Composite inks were prepared using an SF solution and $\mathrm{OBC}$ pastes at varying mass fractions of $\mathrm{SF} / \mathrm{OBC}$ $(2 / 1,1 / 1,1 / 2$, and $0 / 1)$, denoted as $2 \mathrm{SF}-1 \mathrm{OBC}$, $1 \mathrm{SF}-$ 1OBC, 1SF-2OBC, OSF-1OBC, respectively. HRP solution $(500 \mathrm{U} / \mathrm{mL})$ and $\mathrm{H}_{2} \mathrm{O}_{2}$ solution $(490 \mathrm{mM})$ were added to the mixtures of ink to $5 \%(\mathrm{v} / \mathrm{v})$, respectively. The solids of all inks were kept at $7 \mathrm{wt} \%$. The composite inks were mixed gently with a small plastic spade at room temperature (Fig. 1).

\section{Rheology}

Microrheology of the SF solutions and 1SF-1OBC inks was conducted using a Rheolaser Master (Formulaction Co., France) over a period of $1 \mathrm{~h}$ at $25^{\circ} \mathrm{C}$. Clean $4 \mathrm{~mL}$ glass bottles were used for measurements. The rotational rheological properties of the inks were characterized using a Haake RS150L Rheometer (Thermo Electron Co., Germany). Titanium alloy plates (diameter $=20 \mathrm{~mm}$, gap $=300 \mu \mathrm{m}$ ) were used. All measurements were performed at $25^{\circ} \mathrm{C}$. The inks were brought to equilibrium temperature for $1 \mathrm{~min}$ prior to measurement. Shear viscosity was measured at shear rates ranging from $0.001-100 \mathrm{~s}^{-1}$. Oscillation logarithmic stress sweeps from 1 to $1000 \mathrm{~Pa}$ were performed at a frequency of $1 \mathrm{~Hz}$. The frequency range was $0.1-10 \mathrm{~Hz}$ with a strain constant of $1 \%$, determined from the linear viscoelastic region. Measurement of ink gelation times was performed for $1 \mathrm{~h}$ at a frequency of $1 \mathrm{~Hz}$ and strain of $1 \%$. Low viscosity silicone oil was used to prevent evaporation of water.

\section{D bioprinting}

A BioScaffolder Printer 4.2 (GeSim, Germany) with a $410 \mu \mathrm{m}$ nozzle was used to fabricate the SF-OBC hydrogel scaffolds. Different inks of SF-OBC were introduced into the polyethylene injection cartridge which was then fixed to the $3 \mathrm{D}$ printing device. Two layers of individual constructs $\left(10 \times 10 \mathrm{~mm}^{2}\right.$, line spacing $1.0 \mathrm{~mm}$ ) were prepared to study printability. Detailed printing parameters are shown in Table 1 . The scaffolds were printed at room temperature and 


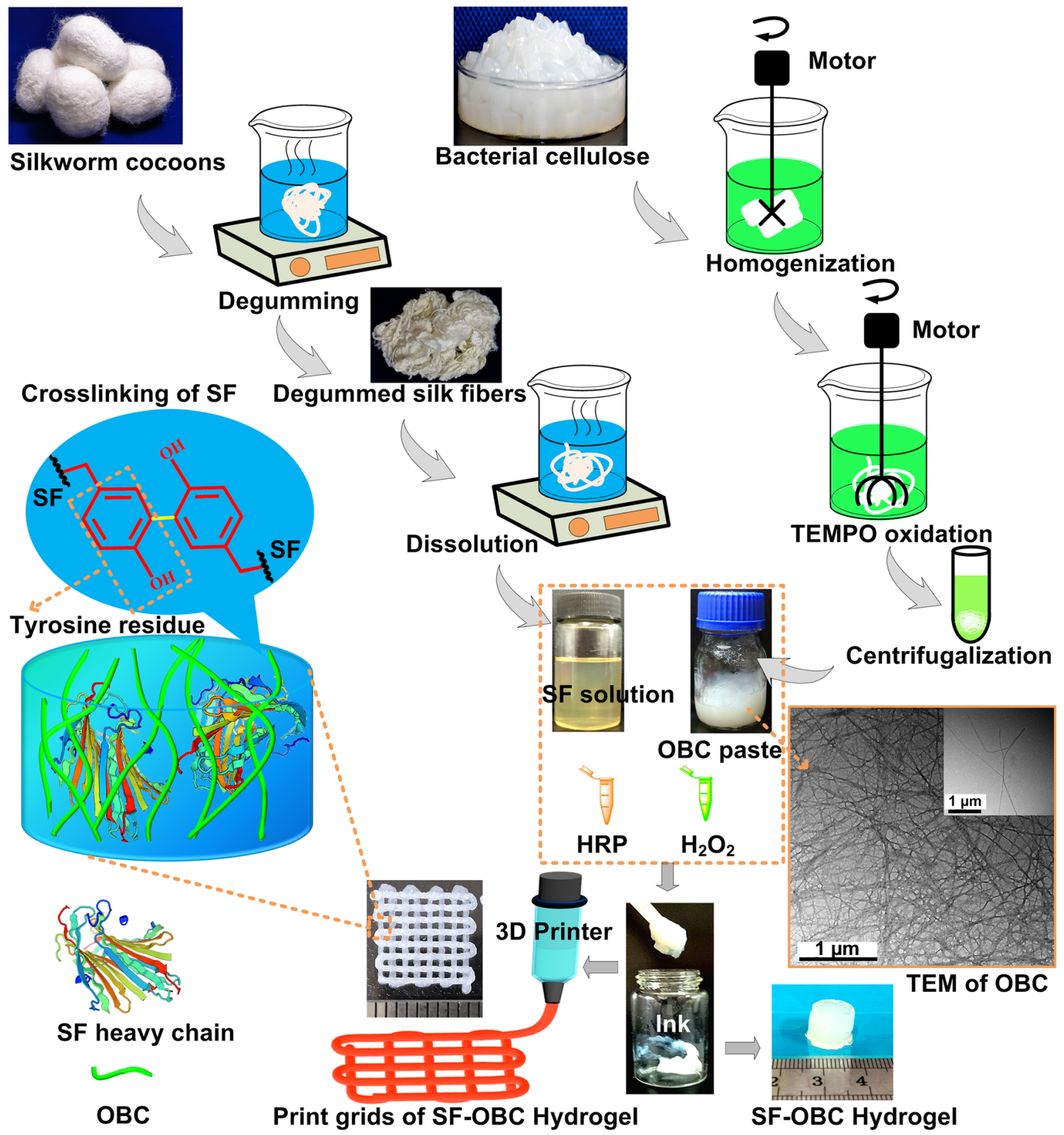

Fig. 1 Process of fabrication SF solution, OBC paste, SF-OBC composite ink and SF-OBC hydrogel. Silk solution was extracted from silkworm cocoons and OBC paste obtained by TEMPO-mediated oxidation of bulk bacterial cellulose. TEM

then maintained at $37{ }^{\circ} \mathrm{C}$ for $1 \mathrm{~h}$ to ensure $\mathrm{SF}$ was sufficiently cross-linked. images of $\mathrm{OBC}$ nanofibrils were acquired at concentrations of $0.01 \mathrm{wt} \%$ and $0.001 \mathrm{wt} \%$ (Inset). Schematic representation of tyrosine residue crosslinking on silk molecule chains

Observation of scaffold morphology

The morphologies of grids were observed using optical microscopy (Olympus CKX41, Japan). The optical images of the scaffolds were analyzed using 
Table 1 Optimal printing parameter combinations ${ }^{\mathrm{a}}$ for SFOBC inks

\begin{tabular}{lll}
\hline Sample code & Pressure (bar) & Printing Speed $(\mathrm{mm} / \mathrm{s})$ \\
\hline 2SF-1OBC & 0.3 & 60 \\
1SF-1OBC & 0.3 & 45 \\
1SF-2OBC & 0.5 & 30 \\
OSF-1OBC & 1.5 & 30 \\
\hline
\end{tabular}

${ }^{a}$ Nozzle diameter $410 \mu \mathrm{m}$, distance between nozzle tip and stage $320 \mu \mathrm{m}$, line space $1 \mathrm{~mm}$, printing layers 2 , angle between layers $0^{\circ} / 90^{\circ}$, printing temperature $25 \pm 1{ }^{\circ} \mathrm{C}$

Image-Pro-Plus 6.0 software to obtain line width $(\mathrm{n}=10)$. Printability $\left(P_{\underline{\underline{r}}}\right)$ was defined as Eq. (1) based on square shapes (Ouyang et al. 2016),

$P_{\mathrm{r}}=L^{2} /(16 A)$

where $L$ represented the perimeter and $A$ represented area. Freeze-dried printed scaffolds were observed using scanning electron microscopy (SEM, JEOL JSM-5600LV, Japan) at a voltage of $10 \mathrm{kV}$ following sputter-coating with gold.

Fourier transform infrared spectroscopy (FT-IR) and X-ray diffraction

FT-IR spectra were acquired using a Nicolet 6700 FTIR spectrometer (Thermo Fisher, USA) equipped with an attenuated total reflection (ATR) accessory at wavenumbers over the range $400-4000 \mathrm{~cm}^{-1}$ at a resolution of $4 \mathrm{~cm}^{-1}$. Synchrotron radiation wideangle X-ray diffraction (SR-WAXD) was performed using a BL15U beamline equipped with a Rayonix165 detector at the Shanghai Synchrotron Radiation Facility. Freeze-dried print lines of each ink were tested perpendicular to the beam direction. Hydrogel scaffolds prepared by casting $20 \mathrm{wt} \%$ SF solution were also characterized for comparision. The diameter of the beamstop was $10 \mathrm{~mm}$ using X-rays at a wavelength of $0.7746 \AA$. The distance from the sample to detector was $185 \mathrm{~mm}$ with an X-ray beam spot size of $3.2 \times 2 \mu \mathrm{m}^{2}$. The circular center of the pattern was calibrated using $\mathrm{CeO}_{2}$. The azimuthal intensity distribution profiles were performed along the arc referred to a (200) lattice plane of cellulose $\mathrm{I}_{\beta}$ crystals. (French 2014) Corresponding full width at half maximum (FWHM) was calculated which was then used in the following Eq. (2) (Sultan and Mathew 2018) to obtain the degree of orientation, $\pi$ :

$\pi=\left(180^{\circ}-\mathrm{FWHM}\right) / 180^{\circ}$

where FWHM is the full width at half maximum of the azimuthal peak.

Mechanical properties

Unconfined compression tests were performed on cast cylinders of composite inks at room temperature. A material testing machine (Instron 5969 USA) equipped with a $100 \mathrm{~N}$ load cell was used. Cylinders with a diameter of $9 \mathrm{~mm}$ and mean height of $6 \mathrm{~mm}$ were prepared. All samples ( $n=5$ per group) were incubated at $37^{\circ} \mathrm{C}$ for $1 \mathrm{~h}$ prior to testing.

Cell culture and cell viability

Lung epithelial stem cells were isolated from human lungs and cultured for three generation. LESCs were cultured in DMEM supplemented with $10 \%$ FBS at $37{ }^{\circ} \mathrm{C}$ in an atmosphere containing $5 \% \mathrm{CO}_{2}$. When LESCs culture had reached nearly $90 \%$ confluence, cells were harvested and $1 \times 10^{5}$ were seeded on each grid ( $1 \mathrm{SF}-1 \mathrm{OBC}, 10 \times 10 \mathrm{~mm}$, line spacing $1.0 \mathrm{~mm}$, 2 layers, nozzle diameter $410 \mu \mathrm{m}$ ). After 3 and 7 days' culture, cells viability and morphology were both evaluated. In addition, $1 \times 10^{4}$ cells were seeded on each sample of cast discs fabricated from 1SF-1OBC hydrogel and cultured for 1, 3 and 7 days. Samples were obtained after different durations of culture for cell proliferation analysis. Tissue culture polystyrene (TCPS) was used as negative control groups. Culture medium was replaced every 2 days.

A live/dead assay kit consisting of Calcein AM/PI was used to visualize cells viability on the printed scaffolds. Samples with 3 and 7 days' culture were washed with phosphate-buffered saline (PBS) then stained for $20 \mathrm{~min}$. Images were acquired using fluorescence microscopy (DMi8, Leica Microsystems GmBH, Germany). For SEM observation, samples were cultured for 7 days then fixed with $2.5 \%$ glutaraldehyde and dehydrated through a series of graded ethanol concentrations $(30,50,70,80,90,95$, $100 \mathrm{vol} \%$ ) prior to freeze-drying overnight. Morphologies of samples were observed using SEM at a voltage of $10 \mathrm{kV}$ after coating with a thin layer of 
gold. Samples on which LESCs had been cultured for 7 days were stained with rhodamine phalloidin and DAPI then observed at wavelengths of $543 \mathrm{~nm}$ and $405 \mathrm{~nm}$ using laser scanning confocal microscopy (LSCM, LSM 880, Carl Zeiss Inc., Germany). Cell proliferation on 1SF-1OBC scaffolds was evaluated using an MTT assay after 1, 3 and 7 days of culture.

\section{Immunofluorescence}

A total number of $1 \times 10^{6}$ LESCs were seeded on 1SF-1OBC scaffolds then cultured for 7 days in growth medium. Samples were washed three times with PBS then fixed in $4 \%$ paraformaldehyde for 30 min, permeabilized with $1 \%$ Triton-X100 in PBS for $10 \mathrm{~min}$, then blocked with $10 \%$ BSA in PBS at $37{ }^{\circ} \mathrm{C}$ for $1 \mathrm{~h}$. Samples were incubated with rabbit anti-Ki67 (1:500 dilution, Abcam) primary antibody (Ki67 expression indicated whether proliferation capability could be maintained) or rabbit anti-p63 (1:600 dilution, Abcam) (p63 expression indicated epithelial phenotype) in blocking buffer at $37^{\circ} \mathrm{C}$ for $1 \mathrm{~h}$. Samples were rinsed three times with PBS then incubated with secondary antibody conjugated to FITC (goat anti-rabbit IgG 1:500 dilution, Abcam) at room temperature for $1 \mathrm{~h}$. Nuclei were stained with DAPI. Fluorescence images of stained samples were acquired by fluorescence microscopy.

\section{Statistical analysis}

At least three groups were compared in all experiments. Data are expressed as mean value \pm standard deviation. One-way ANOVA tests were used to analyze differences between groups. $P<0.05$ was considered statistically significant.

\section{Results and discussion}

Effects of addition of OBC on rheological behavior of SF inks

Approximately $70 \%$ of the SF amino acid sequence consisted of repeat units of glycine, alanine and serine (Mita et al. 1988). Tyrosine residues with a 4-hydroxyphenyl side groups occupied 5.3\% of silk fibroin's composition (Chirila et al. 2017; Pereira et al. 2015) and can be used in chemical crosslinking, as shown in
Fig. 1. SF hydrogel gelation time was significantly influenced by the relative contents of HRP and $\mathrm{H}_{2} \mathrm{O}_{2}$. Higher HRP content resulted in reduced gelation time and higher $\mathrm{H}_{2} \mathrm{O}_{2}$ content resulted in the converse (Yan et al. 2016). For the pregel of SF based ink driven by enzyme, very limited crosslinking requested to remain its printable throughout the printing procedure. Figure 2a displays the gelation time of SF solution and SF-OBC composite ink under catalyzed crosslinking of $\mathrm{HRP} / \mathrm{H}_{2} \mathrm{O}_{2}$. The duration of gelation of SF solution changed as the volume ratio of HRP and $\mathrm{H}_{2} \mathrm{O}_{2}$ was modified from $2 / 1$ to $1 / 1$. To ensure sufficient gelation time for printing, a ratio of $\mathrm{V}(\mathrm{HRP}) / \mathrm{V}\left(\mathrm{H}_{2} \mathrm{O}_{2}\right)=1 / 1$ was selected for the preparation of SF-OBC composite inks. SF-OBC composite inks with a relatively slow gelation process to maintain printability (Fig. 2a). In addition, a sol-gel transition occurred over a narrow region of time for the SF solution (Fig. 2b), while there was a broad time window in which SF-OBC composite inks were close to the critical point at the interface between liquid and solid (Fig. 2b). Therefore, it was not possible to obtain shape retention characteristics for $\mathrm{SF} / \mathrm{HRP} / \mathrm{H}_{2} \mathrm{O}_{2}$ inks prior to gelation, to allow smooth extrusion through the nozzle after gelation in the syringe. A strategy to maintain printability by adding OBC paste to SF inks was tested. Dispersed nanofibrils morphology of the bacterial cellulose following TEMPO-mediated oxidation is shown in TEM images in Fig. 1. Native BC fibrils displayed an external network structure. Mechanical treatment alone was hardly sufficient to disintegrate the cellulose fibers into a homogeneous suspension of separate microfibrils (Moon et al. 2011). Furthermore, there were large numbers of hydroxyl groups on the $\mathrm{BC}$ nanofibers, resulting in strong intra/intermolecular hydrogen bonds (Moon et al. 2011). The formation of aggregates caused a considerable barrier for the processing of the $\mathrm{BC}$. However, after a number of hydroxyl groups of the BC were converted into carboxyl groups, the negatively charged nanofibrils dispersed well due to repulsive forces. The complex moduli of SF-OBC composite inks began to increase at approximately $1000 \mathrm{~s}$, indicating the initiation of SF chain crosslinking, as displayed in Fig. 2c. All complex moduli of the composite inks exhibited a similar tendency with different concentrations of OBC. In addition, the complex moduli increased with increasing OBC ratio in the SF-OBC composite inks, as indicated by the red arrow in Fig. 2c. It has been 

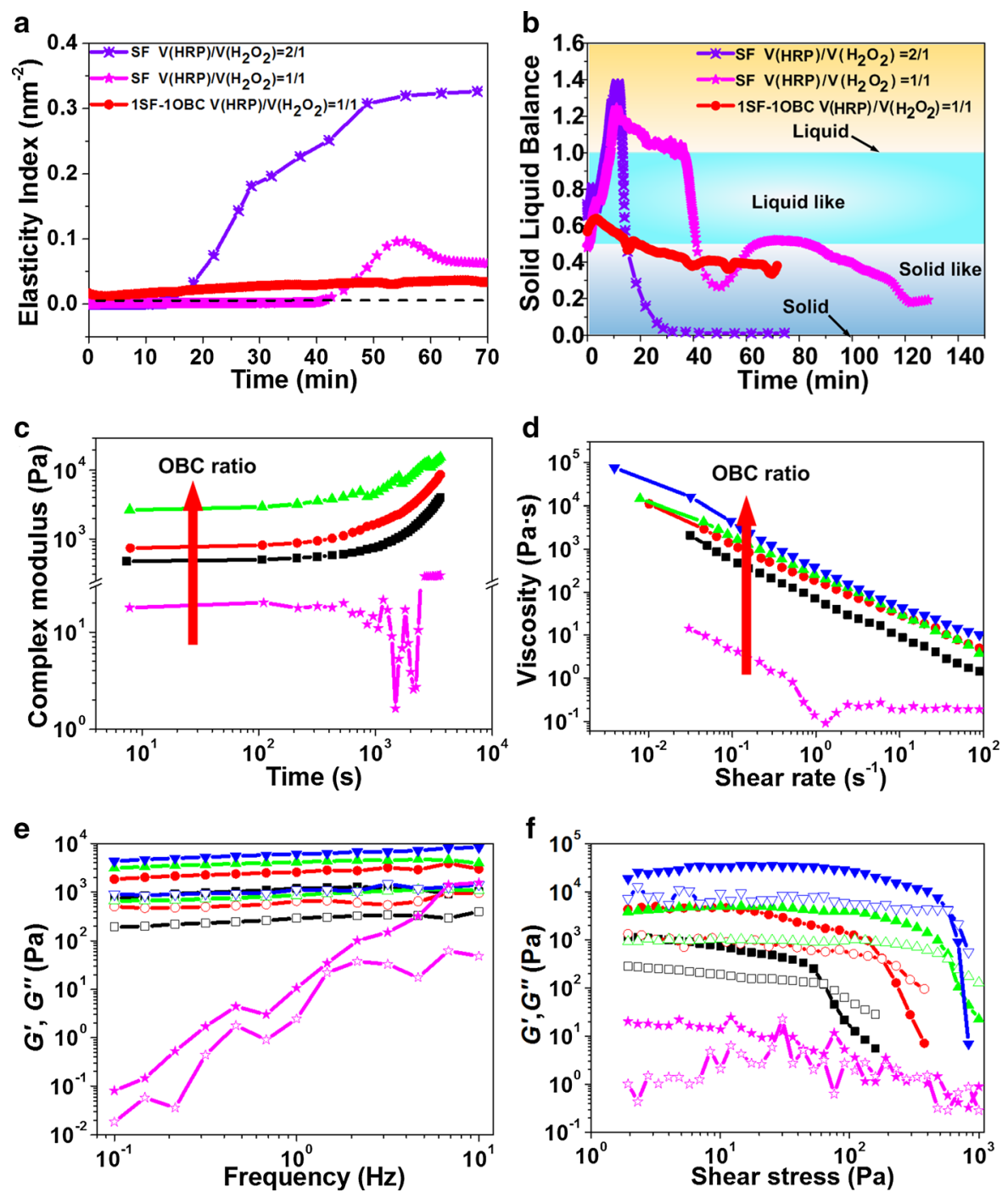

Fig. 2 Rheological behavior of SF solution and SF-OBC inks. a Elasticity index and b solid liquid balance (SLB) of SF solutions and SF-OBC inks as a function of time, obtained using micro-rheometer. Values of SLB larger than 0 but smaller than 0.5 indicate that inks were predominantly in a solid-like state, while $0.5<\mathrm{SLB}<1$ indicates that inks existed mostly in a viscous liquid-like state. SLB $=1$ and SLB $=0$ represent pure liquid and pure solid, respectively. SLB $>1$ represents samples

reported that a $\beta$-sheet conformation could be induced in spider silk ink from an amorphous state under shearthinning without clogging (DeSimone et al. 2015). It was impossible to print high concentrations of silk fibroin solution without additives due to frequent clogging during the shearing process (Das et al. 2013). $\mathrm{SF}$ at a concentration of $20 \mathrm{wt} \%$ displayed a tendency to shear-thinning at the low shear rates $\left(<1 \mathrm{~s}^{-1}\right)$ but

in an unstable state. $\mathbf{c}$ Gelation kinetics, $\mathbf{d}$ steady-shear behavior, e storage modulus $\left(G^{\prime}\right.$, solid symbols) and loss modulus $\left(G^{\prime \prime}\right.$, hollow symbols) as a function of frequency and $\mathbf{f}$ oscillatory rheological behavior of SF solution and different ink formula-

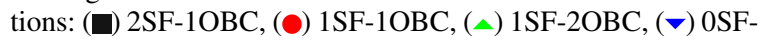
1OBC, $(\star) 20 \mathrm{wt} \%$ SF. Dynamic yield stress is defined as the value when $G^{\prime}=G^{\prime \prime}$. Data in $\mathbf{c}-\mathbf{f}$ were obtained with a rotational rheometer

maintained constant at higher shear rates $\left(>1 \mathrm{~s}^{-1}\right)$, as shown in Fig. 2d. The results indicate that $20 \mathrm{wt} \% \mathrm{SF}$ solution could flow through nozzle under shear force and did not have a negative impact on the printing of composite inks. Unfortunately, the low viscosity of the SF solution restricted printability. However, an OBC paste of $7 \mathrm{wt} \%$ (OSF-1OBC) exhibited not only shear thinning behavior, but also high zero shear viscosity, 
as shown in Fig. 2d. Therefore, cellulose nanofibril pastes were an ideal choice as inks for 3D bioprinting, also commonly used to modify the rheological behavior of 3D printing materials (Abouzeid et al. 2018; Markstedt et al. 2015; Ojansivu et al. 2019). The SF-OBC composite inks displayed similar shearthinning behavior and high zero shear viscosity properties of the $\mathrm{OBC}$ paste alone, as shown in Fig. 2d. Furthermore, OBC pastes significantly enhanced SF solution viscosity, as indicated by the red arrow in Fig. 2d, indicating promotional printability. SF-OBC composite inks displayed greater stability and higher storage moduli $\left(G^{\prime}\right)$ than SF solutions due to the presence of OBC (Fig. 2e). Furthermore, the $G^{\prime}$ of SF-OBC composite inks increased with higher OBC ratios, indicating the promotion of stability. In addition, $G^{\prime}$ values were considerably higher than the $G^{\prime \prime}$ values across the frequency range for all composite inks, providing better initial shape fidelity and structural stability after extrusion. Oscillatory measurements at low strains were performed to assess the viscoelastic properties of the inks (Fig. 2f). Storage moduli $G^{\prime}$ that were larger than loss moduli $G^{\prime \prime}\left(G^{\prime}>G^{\prime \prime}\right)$ prior to the cross point indicated a predominantly elastic behavior at low shear stresses. As stated previously, a solid-like behavior of hydrogel ink is crucial to maintain structural stability and shape fidelity and is therefore desirable for 3D printing (Sultan and Mathew 2018). Composite inks exhibit well-defined dynamic yield stress values $\left(G^{\prime}=G^{\prime \prime}\right)$ (Siqueira et al. 2017) increasing from $63 \mathrm{~Pa}$ (2SF-1OBC) to $593 \mathrm{~Pa}$ (OSF-1OBC) in the present study. The yield stress of $1 \mathrm{SF}-2 \mathrm{OBC}$ was $580 \mathrm{~Pa}$, close to that of OSF-1OBC. Higher OBC ratios resulted in higher shear yield stress, which had to be overcome during printing. This observation may guide the optimization of print parameters.

\section{Printability of SF-OBC composite inks}

The 2SF-1OBC ink had the lowest viscosity (Fig. 2d), thus the printed lines were fused together, so achieving accurate $3 \mathrm{D}$ constructs was not feasible, as shown in Fig. 3a, e. Inks of 1SF-1OBC, 1SF-2OBC and 0SF$1 \mathrm{OBC}$ formed clear pores between print lines and the extruded lines were uniform, as presented in Fig. 3b$\mathrm{d}, \mathrm{f}-\mathrm{h}$. The line width of the printed lines decreased at higher OBC concentrations meant improvement of printing resolution (Fig. 3i). Furthermore, semi- quantitative evaluation was used to characterize printability, as shown in Fig. $3 \mathrm{j}$, based on printed grids, in Fig. $3 \mathrm{e}-\mathrm{h}$. A $P_{\mathrm{r}}$ value approaching 1 indicates higher printability (Kyle et al. 2017). The $P_{\mathrm{r}}$ values of 1SF-1OBC, 1SF-2OBC and OSF-1OBC gradually approached 1 as $\mathrm{OBC}$ content increased. The results demonstrate that $\mathrm{OBC}$ played a key role in facilitating the printability of SF solution. Therefore, scaffolds with more than two layers could be achieved as shown in the inserts of 1SF-1OBC, 1SF-2OBC and OSF1OBC in Fig. 3b-d. Furthermore, 3D construct with ten layers could be printed with ink of $1 \mathrm{SF}-2 \mathrm{OBC}$ as shown in Fig. S1. The printing process with $1 \mathrm{SF}-$ $1 \mathrm{OBC}$ ink can be seen in the video in the Supplementary data. Printing of scaffolds using OBC alone demonstrated the capability of producing high fidelity shaped scaffolds over 10 layers in the present study.

Morphology and structure of printed lines

The morphologies of printed lines were observed after freeze-drying, as shown in Fig. 4a(i-iv). The printed lines became smooth and uniform with higher concentrations of $\mathrm{OBC}$, contributing to the retention of shape. Nanofibrils of OBC were observed in enlarged SEM images. The results in Fig. $4 \mathrm{a}(\mathrm{i}-\mathrm{iii})$ indicate that OBC nanofibrils could be bonded together by SF hydrogel. Without SF, however, the OBC fibers were incompact in the printed lines of OSF-1OBC, Fig. 4a(iv). Furthermore, alignment of the OBC nanofibrils improved with higher ratios of $\mathrm{OBC}$ in the inks. These results were further supported by 2D-WAXD pattern of SF-OBC printed lines (Fig. 4b). Their corresponding 1D-WAXD diffractograms and azimuthal profiles at d-spacing of $3.93 \AA$ of SF-OBC printed lines are shown in Fig. 4c, d, respectively. In Fig. 4c, the broad peak at d-spacing of $4.07 \AA$ indicates the amorphous structure of SF hydrogel which agrees with the results of FTIR in Fig. 5b. The sharp diffraction peaks at d-spacing of $5.28 \AA, 3.95 \AA, 2.58 \AA$ correspond respectively to (110), (200), (004) planes of OBC (cellulose I $\beta$ ) (French 2014). The diffraction peaks of OBC are significantly enhanced at d-spacing of $2.58 \AA$ as the increase ratio of OBC. As shown in Fig. 4b, the arc patterns, corresponding to reflections of the (200) lattice planes of OBC, became clearer as OBC content increased from (i) to (iv). This suggests that improved alignment of OBC fibers occurred along the longitudinal axis of the print lines. To further assess the 

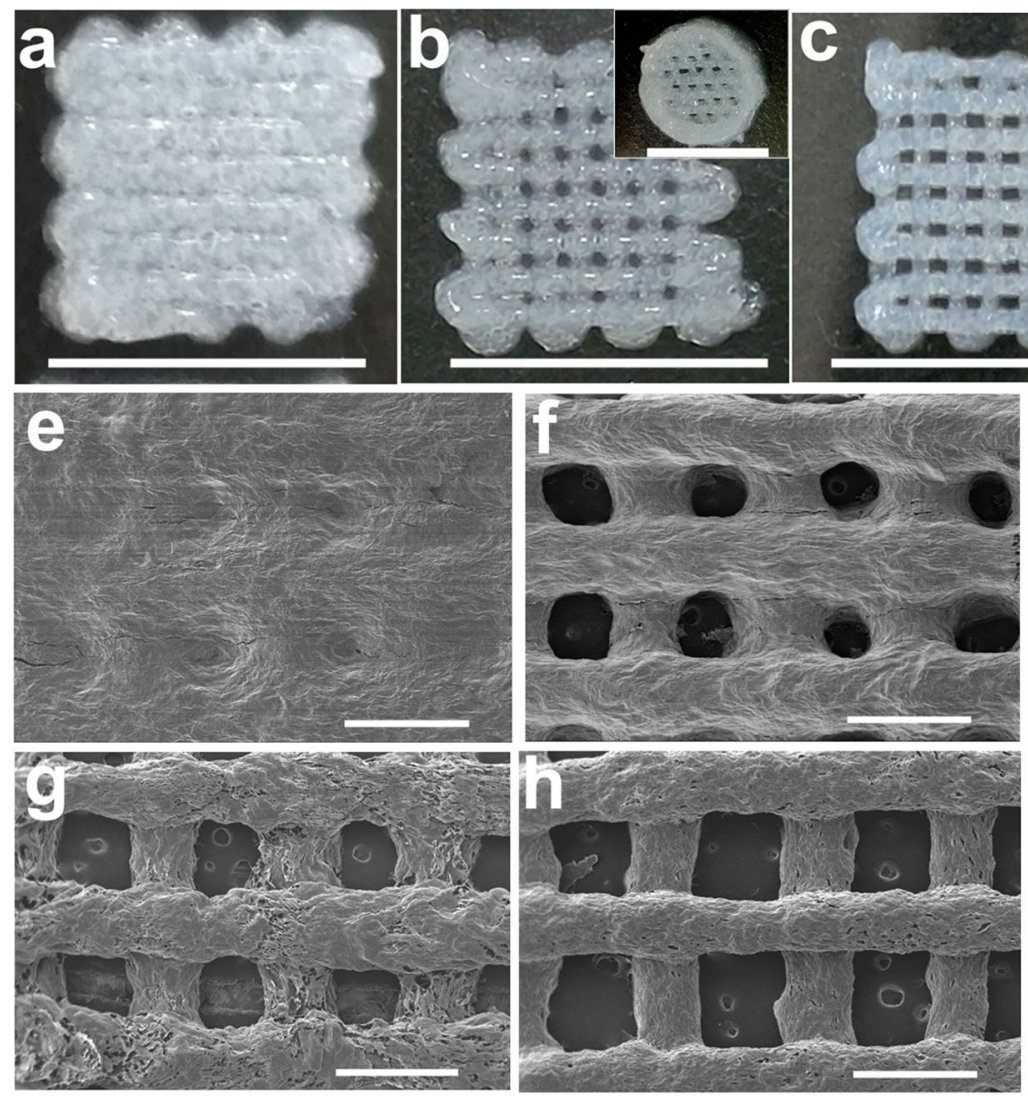
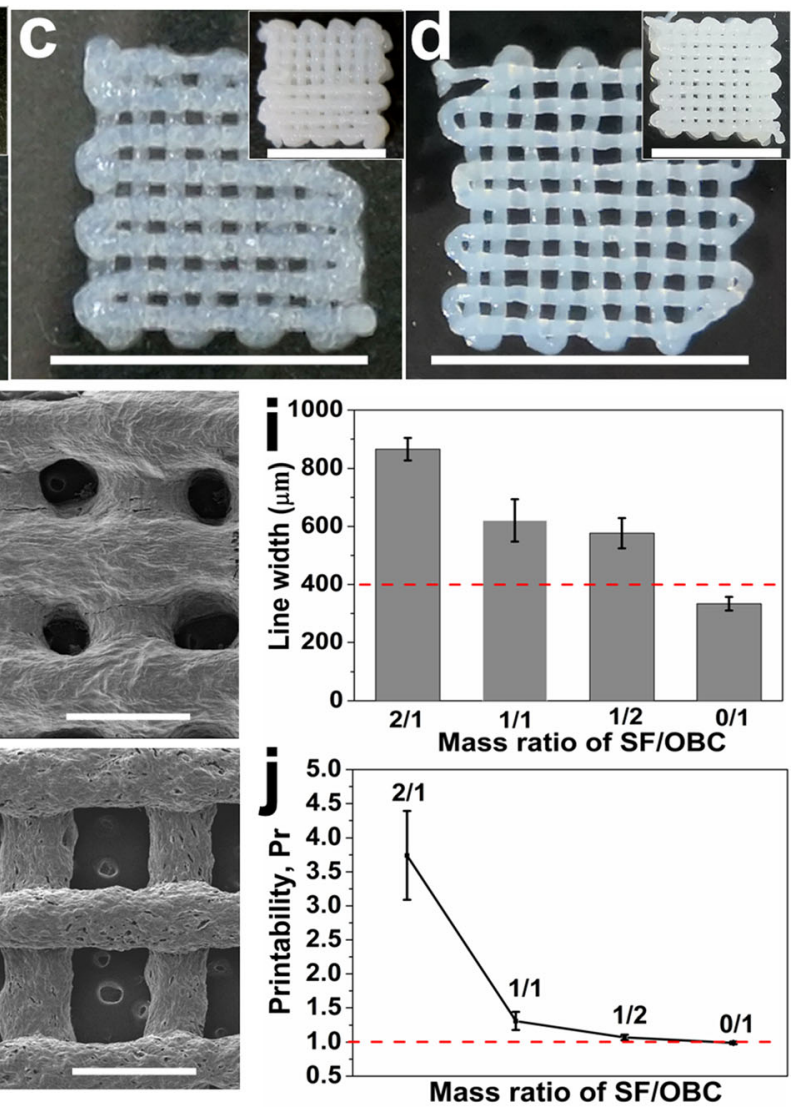

Fig. 3 Printability of different SF-OBC inks. a-d Grids of two crossing layers printed from the four inks a $2 \mathrm{SF}-1 \mathrm{OBC}$, b $1 \mathrm{SF}-$ $1 \mathrm{OBC}$, c $1 \mathrm{SF}-2 \mathrm{OBC}$, and d OSF-1OBC. Scale bar $=10 \mathrm{~mm}$. Inserts in $\mathbf{b}-\mathbf{d}$ indicates structs with more than two layers printed

orientation of nanofibrils in the printed lines, azimuthal intensity distribution (Fig. 4d) and degree of orientation $(\pi)$ of the lattice plane (200) which has d-spacing of $3.93 \AA$ (Fig. 4c) for OBC were calculated. The degree of orientation of nanofibrils in 2SF1OBC, 1SF-1OBC, 1SF-2OBC and 0SF-1OBC was $31 \%, 60 \%, 61 \%$, and $69 \%$, respectively. These results were in good agreement with the SEM results in Fig. 4a. As noted in Table 1, high OBC content ink required greater printing pressure, which might also contribute to the orientation of nanofibrils. It has been reported that controlled filler alignment represents a wide range of applications including improved structural properties of composites in addition to enhanced cell growth in nanofibrous scaffolds for tissue engineering (Prince and Kumacheva 2019; Siqueira et al. 2017; Song et al. 2017). Thus, alignment of OBC nanofibers along their longitudinal direction may also with their corresponding inks. SEM images of e 2SF-1OBC, f $1 \mathrm{SF}-1 \mathrm{OBC}, \mathbf{g} 1 \mathrm{SF}-2 \mathrm{OBC}$, and h 0SF-1OBC. Scale bar $=1$ $\mathrm{mm}$. Line width (i) and semi-quantitative $P_{\mathrm{r}}$ value $(\mathbf{j})$ of printed constructs with different mass ratios of SF/OBC

have promising applications in tissue engineering to mimic natural tissues or organs. Note that porous structures on the surface of print lines were covered during the post-treatment at $37{ }^{\circ} \mathrm{C}$. However, hydrogels of SF-OBC showed the porous structure (Fig. S2) at their cross sections after equilibrium swelling in deionized water. Moreover, nanofibrils of OBC became visible as higher ratio of $\mathrm{OBC}$ mixed in hydrogels from 2 SF-1OBC to 1 SF-2OBC in Fig. S2.

Structural and mechanical properties

FTIR spectra of $\mathrm{BC}$ and $\mathrm{OBC}$ are displayed in Fig. 5a. The peak in the FTIR spectrum at $1647 \mathrm{~cm}^{-1}$ of BC representing the hydroxy methyl group $\left(\mathrm{CH}_{2} \mathrm{OH}\right)$. Peak at $1727 \mathrm{~cm}^{-1}$ of $\mathrm{OBC}$ is related to the $\mathrm{C}=\mathrm{O}$ stretching vibration of the carboxylic acid group (Fig. 5a), indicating successful oxidation of the 


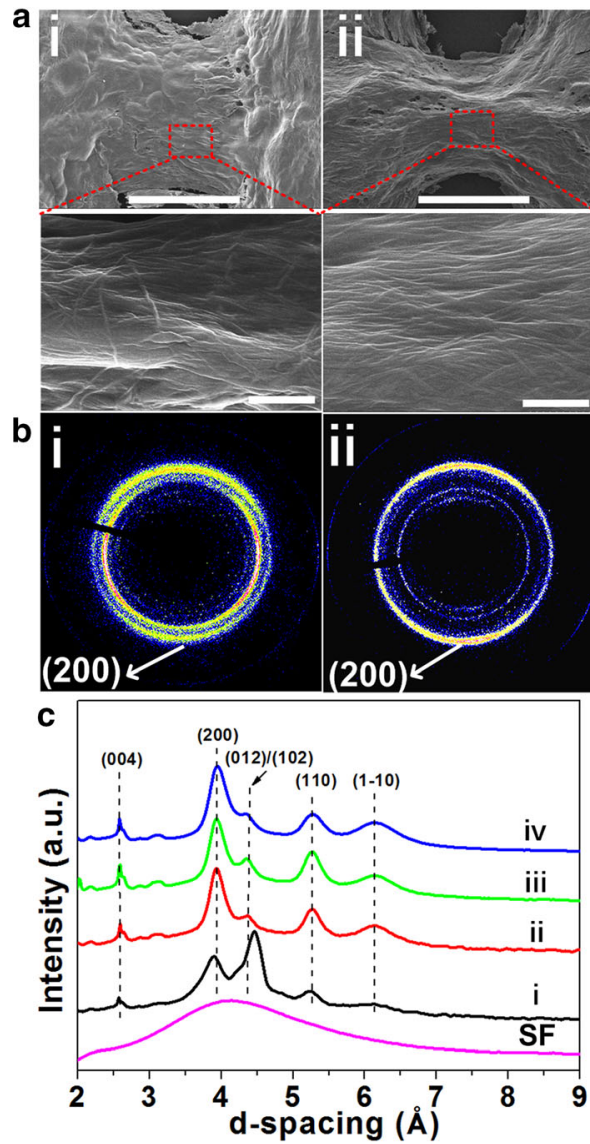

Fig. 4 Morphology and structure of printed lines from SF-OBC inks. a SEM images, b 2D WAXD patterns, c 1D SR-WAXD diffractograms and $\mathbf{d}$ azimuthal intensity distributions of printed lines of (i) $2 \mathrm{SF}-1 \mathrm{OBC}$, (ii) $1 \mathrm{SF}-1 \mathrm{OBC}$, (iii) $1 \mathrm{SF}-2 \mathrm{OBC}$, and (iv)

hydroxyl groups of $\mathrm{BC}$ on $\mathrm{C} 6$ at the surface of fibers. FTIR spectra of printed SF-OBC grids as well as SF hydrogel are shown in Fig. 5b. Peaks at $1026 \mathrm{~cm}^{-1}$, $1058 \mathrm{~cm}^{-1}, 1108 \mathrm{~cm}^{-1}$ and $1157 \mathrm{~cm}^{-1}$ (Fig. 5a) correspond to C6-O, C3-O, C2-O, C1-O-C4 stretching vibrations, respectively, representing the characteristic bands of $\mathrm{BC}(\mathrm{OBC})$ (Lai et al. 2014), appearing in 2SF-1OBC, 1SF-1OBC and 1SF-2OBC spectra (Fig. 5b). The carboxyl groups in OBC paste reduced adhesion between the BC nanofibers, which were well dispersed in the paste (Lai et al. 2014). In this study, the oxidation process was maintained for $1 \mathrm{~h}$. In Yao's work (Yao et al. 2017), the ultimate carboxylate groups were about $0.65 \mathrm{mmol} / \mathrm{g}$ after $1 \mathrm{~h}$ reaction and kept unchanged even by multiple trials. The peak at $3348 \mathrm{~cm}^{-1}$ was assigned to $\mathrm{OH}$ stretching in $\mathrm{BC}$ and OBC (Fig. 5a). The appearance of a broad band
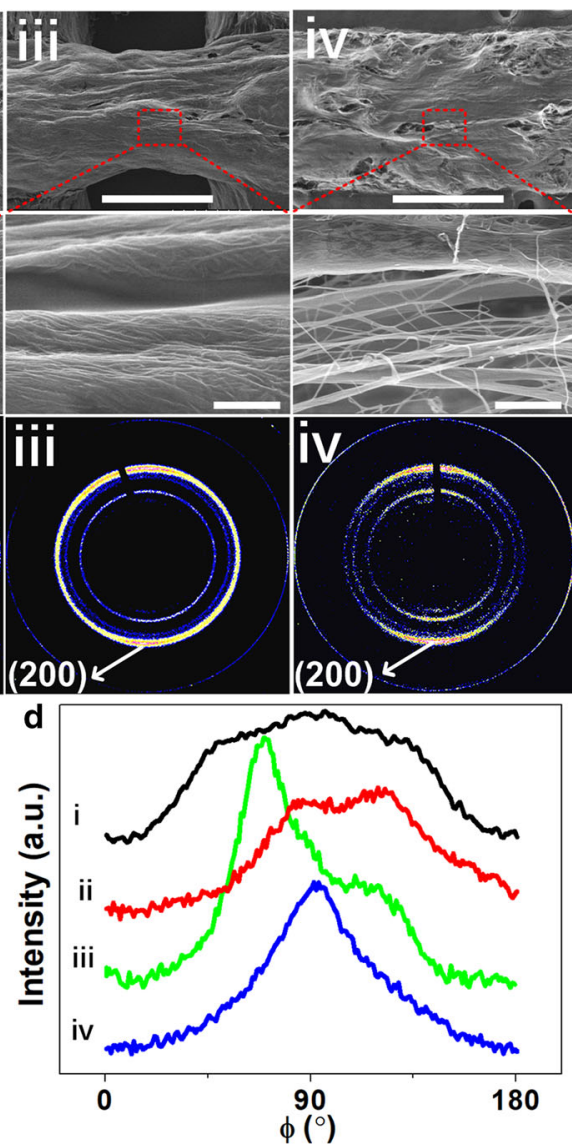

OSF-1OBC. The 1D SR-WAXD diffractograms of SF hydrogel from $20 \mathrm{wt} \%$ SF solution are also shown in $\mathbf{c}$ for comparison. Scale bars in first and second lines are $500 \mu \mathrm{m}$ and $1 \mu \mathrm{m}$, respectively

around $3348 \mathrm{~cm}^{-1}$ in $2 \mathrm{SF}-1 \mathrm{OBC}, 1 \mathrm{SF}-1 \mathrm{OBC}$, and 1SF-2OBC (Fig. 5b) was associated with hydrogen bond interactions between $\mathrm{OBC}$ and SF.

The FTIR spectral regions $1700-1600 \mathrm{~cm}^{-1}$ and $1600-1500 \mathrm{~cm}^{-1}$ are attributable to amide I and amide II, respectively due to the absorption of the peptide backbone, spectra that are commonly used for the analysis of secondary structures in SF. The regions at $1630-1610 \mathrm{~cm}^{-1}$ in amide $I$ and $1520-1510 \mathrm{~cm}^{-1}$ in amide II were assigned to silk II secondary structure while the regions at $1660-1640 \mathrm{~cm}^{-1}$ in amide I and $1542-1535 \mathrm{~cm}^{-1}$ in amide II were assigned to silk I conformation (Leisk et al. 2010; Oliveira Barud et al. 2015). Peaks at $1651 \mathrm{~cm}^{-1}$ and $1537 \mathrm{~cm}^{-1}$ in $1 \mathrm{SF}-$ 2OBC, 1SF-1OBC, 2SF-1OBC, and 20wt\% SF (Fig. $5 b)$ correspond to the conformation of silk I ( $\alpha$ helices and $\beta$-turns), exhibiting no significant 

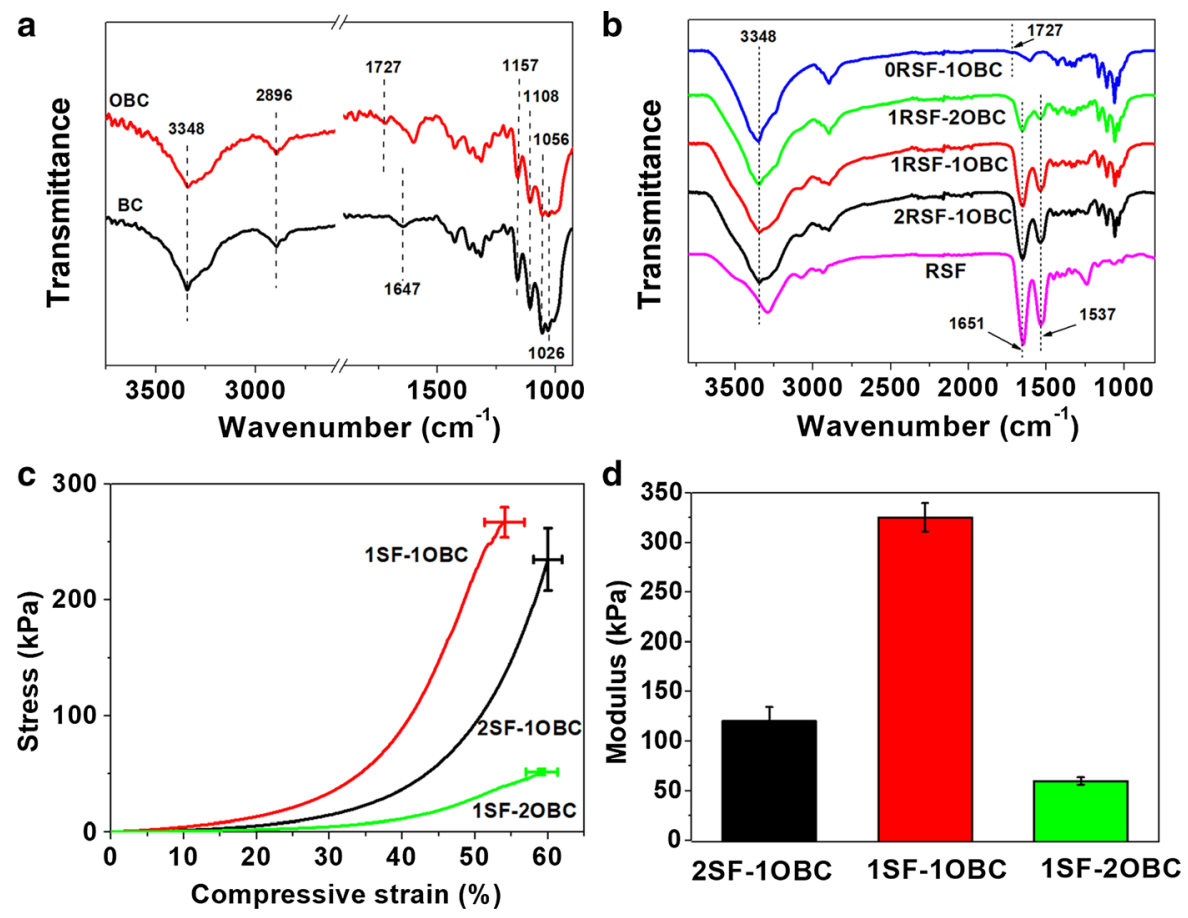

Fig. 5 Structure and mechanical properties of SF-OBC hydrogels. a FTIR spectra of BC and OBC. b FTIR spectra of printed grids of 2SF-1OBC, 1SF-1OBC, 1SF-2OBC, and 0SF1OBC. SF hydrogel fabricated using $20 \mathrm{wt} \%$ SF solution is

difference in intrinsic SF in aqueous solution. As a result, SF hydrogels crosslinked using $\mathrm{HRP} / \mathrm{H}_{2} \mathrm{O}_{2}$ mostly consisted of random coils, easily acquiring the conformational transition from random coil to $\beta$-sheet in alcohol or in vitro or in vivo conditions ( $\mathrm{Su}$ et al. 2017; Yan et al. 2016).

Compressive strength was evaluated using cast discs of SF-OBC hydrogels following crosslinking. SF-OBC hydrogels consisted of SF networks with dityrosine formation with large numbers of interpenetrating OBC nanofibrils, as shown in the schematic presentation of Fig. 1. Enzymatically formed SF hydrogel exhibited excellent elasticity and resilience due to the covalent dityrosine bonds capable of withstanding 3600 cycles at $10 \%$ strain. However, the compressive stiffness of the SF hydrogel was only $0.2-10 \mathrm{kPa}$, limited practical application due to poor rigidity (Partlow et al. 2014). The stress-strain curves for SF-OBC hydrogels are displayed in Fig. 5c. The hydrogel 1SF-1OBC had the highest compressive strength at $267 \pm 13 \mathrm{kPa}$ compared with $2 \mathrm{SF}-1 \mathrm{OBC}$ and 1SF-2OBC. The compressive strain of all SF-OBC hydrogels was greater than $50 \%$. The compressive

shown in b for comparison. c Stress-strain curves of cast SFOBC composite hydrogel disks under unconfined compression test. d Compressive modulus (tangent modulus) of the hydrogel disks at $30 \%$ strain

stiffness at $30 \%$ strain is shown in Fig. 5d. The $1 \mathrm{SF}-$ 1OBC hydrogel exhibited the largest compressive modulus of $325 \pm 14 \mathrm{kPa}$, an order of magnitude higher than that of reported SF hydrogel (Partlow et al. 2014), which compressive stiffness was below $10 \mathrm{kPa}$. Compared with the 2SF-1OBC hydrogel, 1SF-1OBC hydrogel with greater OBC content provided sufficient strength and stiffness. However, when the mass ratio of SF/OBC was altered from $1 / 1$ to $1 / 2$, the mechanical properties of $1 \mathrm{SF}-2 \mathrm{OBC}$ clearly deteriorated. For hydrogels 2 SF-1OBC and 1 SF-1OBC, the SF component acted as a continuous phase, while the OBC component displayed a dispersed phase in the hydrogel at the same solid content. As mentioned above, the enzymatically crosslinked SF hydrogel displayed excellent elasticity but poor stiffness. Conversely, OBC nanofibrils were demonstrated to be outstanding materials, providing sufficient rigidity due to high crystallinity. In addition, large numbers of hydrogen bonds formed between the SF molecular chains and OBC nanofibrils. These contributed to the higher strength and stiffness but relatively lower strain of 1SF-1OBC compared with 2SF-1OBC. However, in 
the case of 1SF-2OBC, a phase transition might have occurred from SF to OBC continuous phase (Fig. S2bd). Too many defects were formed in the SF hydrogel and it was not possible to "lock" the OBC with insufficient SF crosslinking (Fig. S2d). Thus 1SF2OBC exhibited poor strength and stiffness. As a result, 1SF-1OBC showed the best combination between $\mathrm{SF}$ and $\mathrm{OBC}$ among three kinds of hydrogels of 2SF-1OBC, 1SF-1OBC, 1SF-2OBC (Fig. S2b-d). These results were appeared due to the synergistic effects of the blending and cross-linking of SF-OBC (Campodoni et al. 2020). The swelling ratios of all SF/ OBC composite hydrogels are slightly smaller than that of SF hydrogel due to inhibition of OBC nanofibrils (Fig. S3). Hence, the 1SF-1OBC ink was chosen for the preparation of printed scaffolds in subsequent experiments. In addition, many strategies such as immersion in PBS or alcohol can be used to further improve the mechanical properties of the SFOBC hydrogels.

\section{LESC proliferation and cellular response}

The biocompatibility and potential for construction of a lung tissue model using printed SF-OBC hydrogel scaffolds were evaluated using LESCs. LESCs were seeded on 1SF-1OBC scaffold and cultured for 3 and 7 days. The LESCs adhered and proliferated well on the scaffold in growth medium, as shown in Fig. 6a-f. The MTT results (Fig. 6i) indicate that the LESCs grew faster on the scaffolds than TCPS from days 1-3. This is probably because grooved structure formed by OBC nanofibrils on the surface of printed 1 SF-1OBC scaffolds, which benefited to the initial adhesion and proliferation of LESCs (Fig. 6f). This kind of grooved topological surface has also been proved to be competitive in cell culture than flat substrate of TCPS (Campodoni et al. 2020; Kim et al. 2012). Cell proliferation on 1 SF-1OBC was not significantly different from the TCPS control after 7 days. Similar results were also reported in $\mathrm{BC} / \mathrm{SF}$ scaffolds, that exhibit biocompatibility (Chen et al. 2017; Oliveira Barud et al. 2015; Wang et al. 2019). It can be seen from Fig. 6c, d, f that cells on the printed lines exhibited anisotropic topography and aligned along their longitudinal axis, also the direction of orientation of OBC nanofibrils. In lung tissues, epithelial cells are oriented in the lining of the airway (El-Hashash and Warburton 2011; Plosa et al. 2012). The printed SF-
OBC hydrogel scaffolds with aligned OBC nanofibrils could be used to achieve ECM remodeling of the lung tissue. Orientation of the OBC nanofibrils in the printed lines provide physical cues and consequently influence cell fate. Moreover, after culture on scaffolds for 7 days, LESCs maintained the ability to proliferate, as demonstrated by Ki67 expression (Fig. 6g) and epithelial phenotype, as indicated by p63 expression (Fig. 6h). As for freshly isolated pneumocytes, they generally lose their proliferative capacity and phenotype over the first 3-5 days of standard cell culture (Ghaedi et al. 2014; Poon et al. 2018). Therefore, it is critical important to obtain these cells by the differentiation of corresponding stem cells after extensive proliferation (Miller et al. 2019). As a result, the $3 \mathrm{D}$ printed $1 \mathrm{SF}-1 \mathrm{OBC}$ scaffold represents a biomimetic matrix similar to lung tissue that may also supports further epithelial differentiation of LESCs. In addition, cellulose materials alone showed a slow degradation due to their packed molecular structure and the lack of cellulose-degradation enzymes in animals. Moreover, the foreign body reaction is stimulated by cellulose materials due to their slow degradation in vitro or in vivo (Rashad et al. 2019). However, SF/BC hydrogel with 5wt $\%$ BC displayed a fast degradation and lost almost $90 \%$ weight within a month (Fig. S4), which was ascribed to the main component of SF hydrogel with amorphous structure. Moreover, the degradation of SF hydrogel could be further accelerated with protease XIV (Yan et al. 2016). In addition, the degradability of BC could be induced by modification with varieties of strategies and thus formed the derivatives which evoked mild to moderate foreign body reactions (Stalling et al. 2009; $\mathrm{Wu}$ et al. 2012). Overall, printed scaffolds with SFOBC hydrogels present a promising application in lung tissue engineering.

\section{Conclusions}

In the present study, SF-OBC composite hydrogel inks were successfully prepared for extrusion-based 3D printing. The viscoelastic properties of SF hydrogel inks were modified by OBC nanofibrils pastes. The SF-OBC composite inks exhibited excellent shear thinning behavior with reversible stress softening, thus producing a novel silk-based ink for 3D printing. Shape fidelity and fiber alignment were enhanced by 

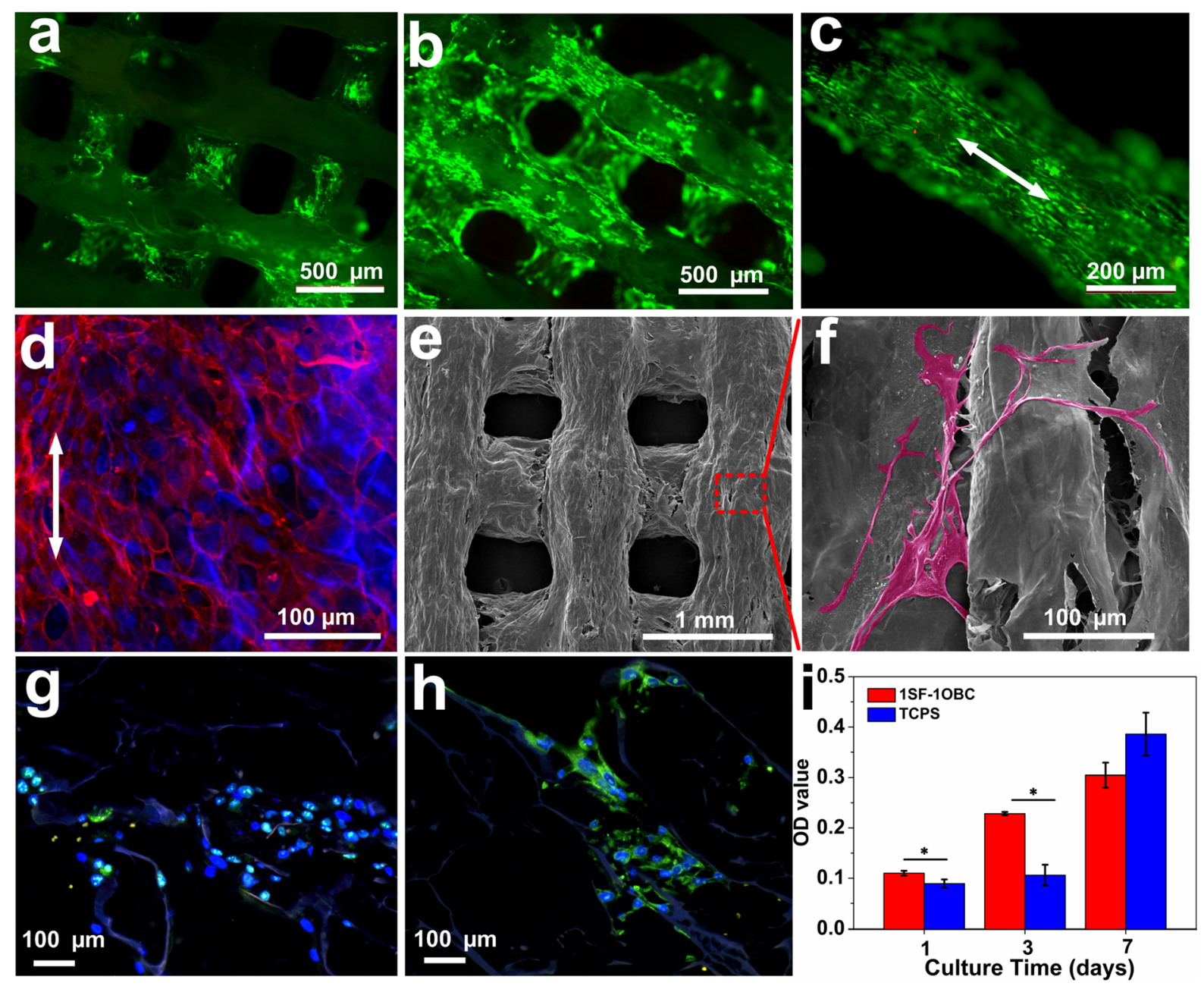

Fig. 6 Cytocompatibility and cellular response of 1SF-1OBC scaffolds in vitro. LESCs seeded on printed 1SF-1OBC scaffolds cultured in growth medium for a 3 days and $\mathbf{b}$, c 7 days and stained using a live (green)/dead (red) assay kit. d LSCM images of LESCs, blue (DAPI) for the nuclei and scaffolds, red (rhodamine labeled phalloidin) for cytoskeleton. c, d LESCs aligned parallel to the longitudinal axis (labeled by white arrow) on the printed filament. e SEM images of cell

the incorporation of $\mathrm{OBC}$ in the printed scaffolds. Three-dimensional construct with ten layers was achieved by ink of 1SF-2OBC. Oxidative OBC nanofibrils not only improved printability but also promoted the mechanical properties of the SF-OBC hydrogel. SF-OBC hydrogel with SF/OBC ratio of $1 / 1$ exhibited significantly improved compressive stiffness of $325 \pm 14 \mathrm{kPa}$ at $30 \%$ strain, which was considerably higher than that previously reported. The OBC nanofibrils aligned along the direction of extrusion in the printed lines provided the biomimetic morphology on scaffolds and f partial enlargement in e as labeled with red dashed square. LESCs are falsely colored to aid visualization of the printed line. Immunofluorescent staining of g Ki67 and $\mathbf{h}$ p63 in LESCs on the printed scaffolds after 7 days' culture in growth medium. i MTT results of LESCs on 1SF1OBC scaffolds and TCPS for 1, 3 and 7 days. "*” Statistically significant $P<0.05$

structures of the ECM of lung, contributing to the micro-structure which induced orientation of LESCs. LESCs on SF-OBC hydrogel scaffolds could maintain their capacity of proliferation as well as epithelial phenotype for at least 1 week. Overall, the 3D printed SF-OBC hydrogel scaffolds mimicked lung tissue structure with anisotropic ECM and thus could represent a promising material for the lung tissue regeneration applications. 


\section{Supplementary data}

Optical pictures of 3D construct of printed 1SF-2OBC scaffold after lyophilization. Cross sectional SEM images of SF-OBC hydrogels after equilibrium swelling in deionized water and subsequent lyophilization. Swelling ratio of SF-OBC hydrogels in deionized water at $37{ }^{\circ} \mathrm{C}$. Degradation of regular printable SF95/BC5 hydrogel (5wt\% BC) in PBS at $37{ }^{\circ} \mathrm{C}$. The video of printing process with ink of $1 \mathrm{SF}-$ $1 \mathrm{OBC}$.

Acknowledgments This work was supported by the National Key Research and Development Program of China (2016YFA0201702, 2018YFC1105800), the National Natural Science Foundation of China (21674018, 51703033, 51903045, 81974085,81671451 ), the Fundamental Research Funds for the Central Universities (2232019A3-06, 2232019D3-02, 2232020D-04), the International Cooperation Fund of the Science and Technology Commission of Shanghai Municipality (19520744500), the Program of Shanghai Academic/Technology Research Leader (20XD1400100), and the Natural Science Foundation of Shanghai (20ZR1402400).

\section{Compliance with ethical standards}

Conflict of interest The authors state no conflict of interest.

\section{References}

Abouzeid RE, Khiari R, Beneventi D, Dufresne A (2018) Biomimetic mineralization of three-dimensional printed alginate/tempo-oxidized cellulose nanofibril scaffolds for bone tissue engineering. Biomacromol 19:4442-4452. https:// doi.org/10.1021/acs.biomac.8b01325

Aljohani W, Ullah MW, Zhang XL, Yang G (2018) Bioprinting and its applications in tissue engineering and regenerative medicine. Int J Biol Macromol 107:261-275. https://doi. org/10.1016/j.ijbiomac.2017.08.171

Campodoni E et al (2020) Blending gelatin and cellulose nanofibrils: biocomposites with tunable degradability and mechanical behavior. Nanomaterials 10:1219. https://doi. org/10.3390/nano10061219

Chawla S, Midha S, Sharma A, Ghosh S (2018) Silk-based bioinks for 3d bioprinting. Adv Healthc Mater 7:1701204. https://doi.org/10.1002/adhm.201701204

Chen J, Zhuang A, Shao HL, Hu XC, Zhang YP (2017) Robust silk fibroin/bacterial cellulose nanoribbon composite scaffolds with radial lamellae and intercalation structure for bone regeneration. J Mater Chem B 5:3640-3650. https://doi.org/10.1039/c7tb00485k

Cheng F et al (2019) Generation of cost-effective paper-based tissue models through matrix-assisted sacrificial $3 \mathrm{~d}$ printing. Nano Lett 19:3603-3611. https://doi.org/10.1021/acs. nanolett.9b00583
Chinga-Carrasco G (2018) Potential and limitations of nanocelluloses as components in biocomposite inks for three-dimensional bioprinting and for biomedical devices. Biomacromol 19:701-711. https://doi.org/10.1021/acs. biomac.8b00053

Chirila TV, Suzuki S, Papolla C (2017) A comparative investigation of Bombyx mori silk fibroin hydrogels generated by chemical and enzymatic cross-linking. Biotechnol Appl Bioc 64:771-781. https://doi.org/10.1002/bab.1552

Comber EM, Palchesko RN, Ng WH, Ren X, Cook KE (2019) De novo lung biofabrication: clinical need, construction methods, and design strategy. Transl Res 211:1-18. https:// doi.org/10.1016/j.trsl.2019.04.008

Dai L et al (2019) 3D printing using plant-derived cellulose and its derivatives: a review. Carbohyd Polym 203:71-86. https://doi.org/10.1016/j.carbpol.2018.09.027

Das S et al (2015) Bioprintable, cell-laden silk fibroin-gelatin hydrogel supporting multilineage differentiation of stem cells for fabrication of three-dimensional tissue constructs. Acta Biomater 11:233-246

Das S, Pati F, Chameettachal S, Pahwa S, Ray AR, Dhara S, Ghosh S (2013) Enhanced redifferentiation of chondrocytes on microperiodic silk/gelatin scaffolds: toward tailormade tissue engineering. Biomacromol 14:311-321. https://doi.org/10.1021/bm301193t

DeSimone E, Schacht K, Jungst T, Groll J, Scheibel T (2015) Biofabrication of 3D constructs: fabrication technologies and spider silk proteins as bioinks. Pure Appl Chem 87:737-749. https://doi.org/10.1515/pac-2015-0106

Dorishetty P et al (2020) Tunable biomimetic hydrogels from silk fibroin and nanocellulose. ACS Sustain Chem Eng 8:2375-2389. https://doi.org/10.1021/acssuschemeng. $9 \mathrm{~b} 05317$

El-Hashash AH, Warburton D (2011) Cell polarity and spindle orientation in the distal epithelium of embryonic lung. Dev Dynam 240:441-445. https://doi.org/10.1002/dvdy.22551

Fernandes EM, Pires RA, Mano JF, Reis RL (2013) Bionanocomposites from lignocellulosic resources: properties, applications and future trends for their use in the biomedical field. Prog Polym Sci 38:1415-1441. https://doi.org/ 10.1016/j.progpolymsci.2013.05.013

French AD (2014) Idealized powder diffraction patterns for cellulose polymorphs. Cellulose 21:885-896. https://doi. org/10.1007/s10570-013-0030-4

Ghaedi M, Mendez JJ, Bove PF, Sivarapatna A, Raredon MSB, Niklason LE (2014) Alveolar epithelial differentiation of human induced pluripotent stem cells in a rotating bioreactor. Biomaterials 35:699-710. https://doi.org/10.1016/j. biomaterials.2013.10.018

Ghosh S, Parker ST, Wang XY, Kaplan DL, Lewis JA (2008) Direct-write assembly of microperiodic silk fibroin scaffolds for tissue engineering applications. Adv Funct Mater 18:1883-1889

Hu X, Shmelev K, Sun L, Gil ES, Park SH, Cebe P, Kaplan DL (2011) regulation of silk material structure by temperaturecontrolled water vapor annealing. Biomacromol 12:1686-1696

Huang L et al (2019a) Bacterial cellulose nanofibers promote stress and fidelity of 3D-printed silk based hydrogel scaffold with hierarchical pores. Carbohyd Polym 
221:146-156. https://doi.org/10.1016/j.carbpol.2019.05. 080

Huang L et al (2019b) Silk scaffolds with gradient pore structure and improved cell infiltration performance. Mat Sci Eng C-Mater 94:179-189. https://doi.org/10.1016/j.msec.2018. 09.034

Huang W, Xiao Y, Shi X (2019c) Construction of electrospun organic/inorganic hybrid nanofibers for drug delivery and tissue engineering applications. Adv Fiber Mater 1:32-45. https://doi.org/10.1007/s42765-019-00007-w

Jose RR, Brown JE, Polido KE, Omenetto FG, Kaplan DL (2015) Polyol-silk bioink formulations as two-part roomtemperature curable materials for $3 \mathrm{~d}$ printing. ACS Biomater Sci Eng 1:780-788

Jungst T, Smolan W, Schacht K, Scheibel T, Groll J (2016) Strategies and molecular design criteria for 3D printable hydrogels. Chem Rev 116:1496-1539. https://doi.org/ 10.1021/acs.chemrev.5b00303

Kang HW, Lee SJ, Ko IK, Kengla C, Yoo JJ, Atala A (2016) A 3D bioprinting system to produce human-scale tissue constructs with structural integrity. Nat Biotechnol 34:312-319. https://doi.org/10.1038/nbt.3413

Kim DH, Provenzano PP, Smith CL, Levchenko A (2012) Matrix nanotopography as a regulator of cell function. J Cell Biol 197:351-360. https://doi.org/10.1083/jcb. 201108062

Kurisawa M, Lee F, Wang LS, Chung JE (2010) Injectable enzymatically crosslinked hydrogel system with independent tuning of mechanical strength and gelation rate for drug delivery and tissue engineering. $J$ Mater Chem 20:5371-5375. https://doi.org/10.1039/b926456f

Kyle S, Jessop ZM, Al-Sabah A, Whitaker IS (2017) "Printability" of candidate biomaterials for extrusion based 3d printing: state-of-the-art. Adv Healthc Mater 6:1700264. https://doi.org/10.1002/adhm.201700264

Lai C, Zhang SJ, Chen XC, Sheng LY (2014) Nanocomposite films based on TEMPO-mediated oxidized bacterial cellulose and chitosan. Cellulose 21:2757-2772. https://doi. org/10.1007/s10570-014-0330-3

Leisk GG, Lo TJ, Yucel T, Lu Q, Kaplan DL (2010) Electrogelation for protein adhesives. Adv Mater 22:711-715. https://doi.org/10.1002/adma.200902643

Lin YM, Boccaccini AR, Polak JM, Bishop AE (2006) Biocompatibility of poly-DL-lactic acid (PDLLA) for lung tissue engineering. J Biomater Appl 21:109-118. https:// doi.org/10.1177/0885328206057952

Liu J, Sun LS, Xu WY, Wang QQ, Yu SJ, Sun JZ (2019) Current advances and future perspectives of 3D printing naturalderived biopolymers. Carbohyd Polym 207:297-316. https://doi.org/10.1016/j.carbpol.2018.11.077

Malda J et al (2013) 25th anniversary article: engineering hydrogels for biofabrication. Adv Mater 25:5011-5028. https://doi.org/10.1002/adma.201302042

Markstedt K, Mantas A, Tournier I, Avila HM, Hagg D, Gatenholm P (2015) 3D bioprinting human chondrocytes with nanocellulose-alginate bioink for cartilage tissue engineering applications. Biomacromol 16:1489-1496. https://doi.org/10.1021/acs.biomac.5b00188

McCarthy RR, Ullah MW, Booth P, Pei E, Yang G (2019) The use of bacterial polysaccharides in bioprinting. Biotechnol Adv. https://doi.org/10.1016/j.biotechadv.2019.107448
Miller AJ, Dye BR, Ferrer-Torres D, Hill DR, Overeem AW, Shea LD, Spence JR (2019) Generation of lung organoids from human pluripotent stem cells in vitro. Nat Protoc 14:518-540. https://doi.org/10.1038/s41596-018-0104-8

Mita K, Ichimura S, Zama M, James TC (1988) Specific codon usage pattern and its implications on the secondary structure of silk fibroin messenger-rna. J Mol Biol 203:917-925. https://doi.org/10.1016/0022-2836(88)90117-9

Mondrinos MJ, Koutzaki S, Jiwanmall E, Li MY, Dechadarevian JP, Lelkes PI, Finck CM (2006) Engineering threedimensional pulmonary tissue constructs. Tissue Eng 12:717-728. https://doi.org/10.1089/ten.2006.12.717

Moniri M et al (2017) Production and status of bacterial cellulose in biomedical engineering. Nanomaterials-Basel 7:257. https://doi.org/10.3390/nano7090257

Moohan J et al (2020) Cellulose nanofibers and other biopolymers for biomedical applications. Rev Appl Sci-Basel 10:65. https://doi.org/10.3390/app10010065

Moon RJ, Martini A, Nairn J, Simonsen J, Youngblood J (2011) Cellulose nanomaterials review: structure, properties and nanocomposites. Chem Soc Rev 40:3941-3994. https:// doi.org/10.1039/c0cs00108b

Murphy AR, Kaplan DL (2009) Biomedical applications of chemically-modified silk fibroin. J Mater Chem 19:6443-6450. https://doi.org/10.1039/b905802h

Nimeskern L, Avila HM, Sundberg J, Gatenholm P, Muller R, Stok KS (2013) Mechanical evaluation of bacterial nanocellulose as an implant material for ear cartilage replacement. J Mech Behav Biomed 22:12-21. https://doi. org/10.1016/j.jmbbm.2013.03.005

Ojansivu M et al (2019) Wood-based nanocellulose and bioactive glass modified gelatin-alginate bioinks for $3 \mathrm{D}$ bioprinting of bone cells. Biofabrication. https://doi.org/10. 1088/1758-5090/ab0692/meta

Oliveira Barud HG et al (2015) Preparation and characterization of a bacterial cellulose/silk fibroin sponge scaffold for tissue regeneration. Carbohydr Polym 128:41-51. https:// doi.org/10.1016/j.carbpol.2015.04.007

Ouyang L, Yao R, Zhao Y, Sun W (2016) Effect of bioink properties on printability and cell viability for $3 \mathrm{D}$ bioplotting of embryonic stem cells. Biofabrication 8:035020. https://doi.org/10.1088/1758-5090/8/3/035020

Partlow BP et al (2014) Highly tunable elastomeric silk biomaterials. Adv Funct Mater 24:4615-4624. https://doi.org/ 10.1002/adfm.201400526

Pereira RFP, Silva MM, Bermudez VD (2015) Bombyx mori silk fibers: an outstanding family of materials. Macromol Mater Eng 300:1171-1198. https://doi.org/10.1002/mame. 201400276

Plosa EJ, Gooding KA, Zent R, Prince LS (2012) Nonmuscle myosin II regulation of lung epithelial morphology. Dev Dynam 241:1770-1781. https://doi.org/10.1002/dvdy. 23866

Poon JCH et al (2018) Design of biomimetic substrates for longterm maintenance of alveolar epithelial cells. Biomater Sci-Uk 6:292-303. https://doi.org/10.1039/c7bm00647k

Prince E, Kumacheva E (2019) Design and applications of manmade biomimetic fibrillar hydrogels. Nat Rev Mater 4:99-115. https://doi.org/10.1038/s41578-018-0077-9

Rashad A et al (2019) Inflammatory responses and tissue reactions to wood-Based nanocellulose scaffolds. Mat Sci Eng 
C-Mater 97:208-221. https://doi.org/10.1016/j.msec.2018. 11.068

Schwarz S, Avila HM, Rotter N, Gatenholm P (2015) 3D bioprinting of human chondrocyte-laden nanocellulose hydrogels for patient-specific auricular cartilage regeneration. Tissue Eng Pt A 21:S373-S373

Siqueira $G$ et al (2017) Cellulose nanocrystal inks for 3D printing of textured cellular architectures. Adv Funct Mater 27:1604619. https://doi.org/10.1002/adfm.201604619

Song WG, Liu DG, Prempeh N, Song RJ (2017) Fiber alignment and liquid crystal orientation of cellulose nanocrystals in the electrospun nanofibrous mats. Biomacromol 18: 3273-3279. https://doi.org/10.1021/acs.biomac.7b00927

Stalling SS, Akintoye SO, Nicoll SB (2009) Development of photocrosslinked methylcellulose hydrogels for soft tissue reconstruction. Acta Biomater 5:1911-1918. https://doi. org/10.1016/j.actbio.2009.02.020

Su DH, Yao M, Liu J, Zhong YM, Chen X, Shao ZZ (2017) Enhancing mechanical properties of silk fibroin hydrogel through restricting the growth of beta-sheet domains. ACS Appl Mater Inter 9:17490-17499. https://doi.org/10.1021/ acsami.7b04623

Sultan S, Mathew AP (2018) 3D printed scaffolds with gradient porosity based on a cellulose nanocrystal hydrogel. Nanoscale 10:4421-4431. https://doi.org/10.1039/c7nr089 $66 \mathrm{j}$

Sun L, Parker ST, Syoji D, Wang XL, Lewis JA, Kaplan DL (2012) Direct-write assembly of 3d silk/hydroxyapatite scaffolds for bone co-cultures. Adv Healthc Mater 1:729-735. https://doi.org/10.1002/adhm.201200057

Tebyanian H, Karami A, Nourani MR, Motavallian E, Barkhordari A, Yazdanian M, Seifalian A (2019) Lung tissue engineering: an update. J Cell Physiol 234:19256-19270. https://doi.org/10.1002/jcp.28558

Terry AE, Knight DP, Porter D, Vollrath F (2004) PH induced changes in the rheology of silk fibroin solution from the middle division of Bombyx mori silkworm. Biomacromol 5:768-772

Theocharis AD, Skandalis SS, Gialeli C, Karamanos NK (2016) Extracellular matrix structure. Adv Drug Deliver Rev 97:4-27. https://doi.org/10.1016/j.addr.2015.11.001

Wagner DE et al (2014) Three-dimensional scaffolds of acellular human and porcine lungs for high throughput studies of lung disease and regeneration. Biomaterials 35:2664-2679. https://doi.org/10.1016/j.biomaterials.2013.11.078

Wang BX et al (2018) Use of heparinized bacterial cellulose based scaffold for improving angiogenesis in tissue regeneration. Carbohyd Polym 181:948-956. https://doi. org/10.1016/j.carbpol.2017.11.055

Wang K, Ma Q, Zhang Y-M, Han G-T, Qu C-X, Wang S-D (2019) Preparation of bacterial cellulose/silk fibroin double-network hydrogel with high mechanical strength and biocompatibility for artificial cartilage. Cellulose. https:// doi.org/10.1007/s10570-019-02869-0

Wang BX et al (2020) Urethra-inspired biomimetic scaffold: a therapeutic strategy to promote angiogenesis for urethral regeneration in a rabbit model. Acta Biomater 102:247-258. https://doi.org/10.1016/j.actbio.2019.11.026

Wlodarczyk-Biegun MK, del Campo A (2017) 3D bioprinting of structural proteins. Biomaterials 134:180-201

Wu YD, He JM, Cheng WL, Gu HB, Guo ZH, Gao S, Huang YD (2012) Oxidized regenerated cellulose-based hemostat with microscopically gradient structure. Carbohyd Polym 88:1023-1032. https://doi.org/10.1016/j.carbpol.2012.01. 058

Xu WY, Wang XJ, Sandler N, Willfor S, Xu CL (2018) Threedimensional printing of wood-derived biopolymers: a review focused on biomedical applications. ACS Sustain Chem Eng 6:5663-5680. https://doi.org/10.1021/ acssuschemeng.7b03924

Yan LP et al (2016) Tumor growth suppression induced by biomimetic silk fibroin hydrogels. Sci Rep-UK 6:31037. https://doi.org/10.1038/srep31037

Yao JJ, Chen SY, Chen Y, Wang BX, Pei QB, Wang HP (2017) Macrofibers with high mechanical performance based on aligned bacterial cellulose nanofibers. ACS Appl Mater Inter 9:20330-20339. https://doi.org/10.1021/acsami. $6 \mathrm{~b} 14650$

Zheng ZZ et al (2018) 3D bioprinting of self-standing silk-based bioink. Adv Healthc Mater 7:1701026. https://doi.org/10. 1002/adhm.201701026

Publisher's Note Springer Nature remains neutral with regard to jurisdictional claims in published maps and institutional affiliations. 